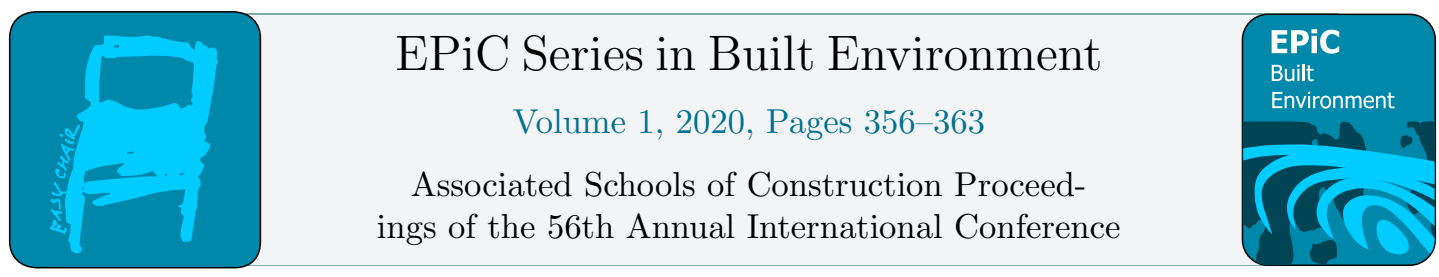

\title{
Quantitative Analysis of the Delay Factors in Oil and Gas Pipeline Projects
}

\author{
Layth Kraidi, Researcher; Raj Shah, PhD, FHEA; Wilfred Matipa,
} PhD, AFHEA; and Fiona Borthwick, PhD, FHEA.

Department of the Built Environment, Faculty of Engineering and

Technology, Liverpool John Moores University.

Liverpool, England, UK

Building new Oil and Gas Pipelines (OGPs) without identifying and analyzing the Influencing Risk Factors (IRFs) could cause project delay and have a significant impact on the safety of the projects at the construction and operation stages. Hence, it is essential to assess the IRFs that are applicable to the OGP projects and manage them by quantifying their impact on the projects in an accurate way. The potential IRFs were identified via an extensive literature review, and they were analyzed using the findings of a questionnaire survey and the fuzzy logic theory. This paper aims to quantify the impact of the recorded IRFs on the project's duration and forecast the probability of the project being completed in time. The methodology of this paper includes allocating the Risk Index (RI) values of each IRF to the work activities of the projects, applying the risk distributing methods, and calculating the impact of the IRFs on the duration of each activity of the project using Monte Carlo Simulation. This paper will be useful in providing a suitable measure for the IRFs in OGPs projects, and will aid in reducing their impact on project duration and improving the certainty of the projects delivery.

Key Words: Oil and gas pipeline projects, Monte Carlo Simulation, construction and pipeline risk, delay, and project duration

\section{Introduction}

Delay is one of the most common problems in construction projects in both developed and developing countries in the majority of projects (Alaghbari et al., 2007). Understanding the delay factors and their level of impact on construction projects may help to avoid or minimize the delay (Shebob et al., 2012). Providing a good knowledge about the Influencing Risk Factors (IRFs) and using analytical or simulation techniques are the most effective methods of risk assessment (Ruwanpura et al., 2004). Kraidi et al. (2019c) used fuzzy logic theory to assess the IRFs with the aim of reducing the uncertainty caused by the lack of data and the prejudices in stakeholders' judgements about their level of impact. Analyzing the impact of the IRFs on the projects at the planning and design stage could help the stakeholders to make sound decisions in response to risk management to keep the delay interruption in the projects to a minimum, as much as possible. However, there is a lack of studies about risk quantification analysis and its impact on Oil and Gas Pipeline (OGP) projects in developing countries like Iraq (Kraidi et al., 2019a and 2019c). 
This paper focuses on analyzing and quantifying the impact of the IRFs on the duration of OGP projects and the probability of completing the pipeline projects on time. It uses fuzzy logic theory and Monte Carlo Simulation (MCS) integrated within the ASTA Powerproject risk simulator as a rational way of simulating the IRFs in OGP projects. A new OGP project recently built in southern Iraq was selected as a case study for evaluating the risk simulation model developed in the paper. The length of the pipe is $164 \mathrm{~km}$ and, when constructed, the pipe will transport the extracted gas from Badra gas field to the shipping point on the gulf in Basra. This project belongs to the Gazprom Neft Badra company; it has been under planning since May 21, 2019, and the targeted delivery date is January 13, 2023. This means the duration of the project is estimated as 3 years and 238 days (1334 days).

\section{Literature Review}

Studies like Morano et al. (2006), and Choong Kog (2018) have analyzed the delay factors in construction projects using a document analysis method. Morano et al.'s (2006) study was limited to construction projects in Jordan, and Choong Kog's (2018) study was limited to construction projects in Portugal, the UK and the US; while These studies did not make any assessment of the delay factors or quantify their impact on the projects. For example, they did not use any kind of survey, computer modelling or simulation methods to analyze the delay factors and quantify their impact on the projects' duration.

Shah (2016) identified the comparative delay factors in construction projects in countries like Australia, Ghana and Malaysia via a questionnaire survey and recommended the potential measures to reduce their impact on the projects. Prasad et al. (2019) used a questionnaire survey to identify and analyze the delay factors in transportation, power and water projects in India. Mpofu et al. (2017) analyzed the delay factors in construction projects in the United Arab Emirates via exploring the perceptions of the clients, the contractors and the consultants. Alaghbari et al. (2007) distributed a questionnaire survey to analyze the delay factors in construction projects in Malaysia. Kadry et al. (2017) analyzed the delay factors in construction projects in 16 countries with a high geopolitical risk. The delay factors considered in this study were analyzed using qualitative document analysis and quantitative risk analysis via engaging with a number of experts in these countries. None of the above-mentioned studies analyzed or simulated the probability of the delay factors associated with the activities of the projects. Moreover, the risk assessment methods used in these studies are limited to their regions of study, which means they cannot be effectively applied to analyze the impact of the delay factors in oil and gas projects and improve the level of safety of these projects elsewhere.

Fallahnejad (2013) used document analysis and a questionnaire survey to identify the main delay factors and analyze their impact on pipeline projects in Iran. Similarly, Ruqaishi and Bashir (2015) investigated the delay factors in the construction of oil and gas projects in Oman as a case study. Sweis et al. (2019) used a questionnaire survey to identify the root causes of the delay factors in gas pipeline projects in Iran. However, these studies did not quantify the potential delay in these projects caused by the IRFs.

Hence, this paper has developed a research methodology that overcomes the highlighted limitations of the previous studies with regard to analyzing and quantifying the impact of the IRFs on the duration of OGP projects. The adopted methodology in the paper is discussed in the next section.

\section{Research Methodology}


This paper uses a mixture of qualitative and quantitative research methodology to analyze the IRFs in OGP projects in Iraq and to quantify their impact on the duration of these projects. Figure 1 shows the information flow diagram with the risk management steps adopted in the study.

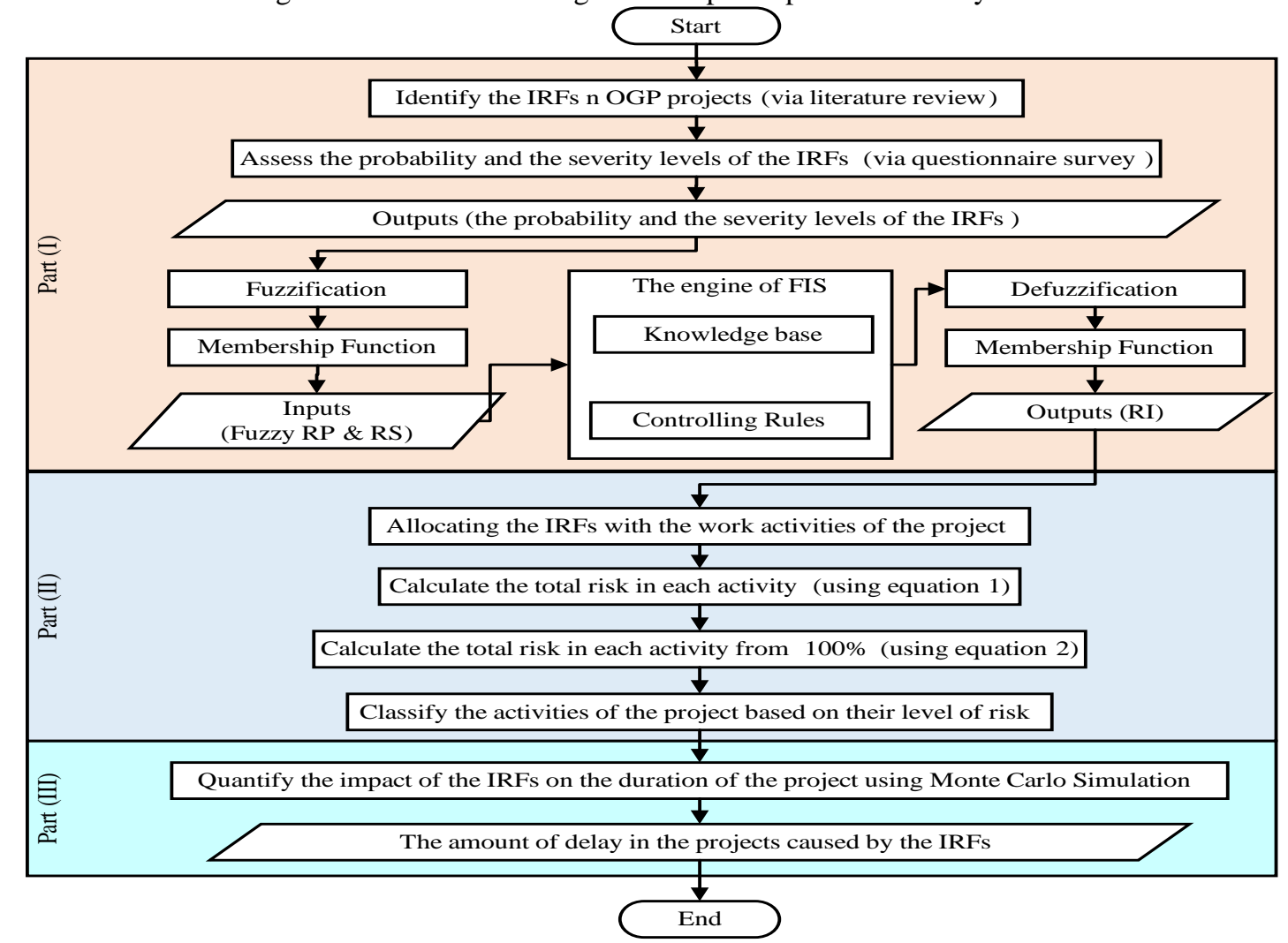

Figure 1. The information flow chart and the risk management processes adopted in the paper.

As shown in figure 1, the risk management process is divided into three parts. Part (I) describes the process of identifying and assessing the IRFs in OGP projects in Iraq, using the following steps.

1- Firstly, the IRFs were identified via an extensive literature review about the risks in OGP projects worldwide in order to overcome the problem of data scarcity about the IRFs in OGP projects in Iraq (Kraidi et al., 2017 and 2019a).

2- The Risk Probability (RP) and Risk Severity (RS) levels of the IRFs were identified via conducting a questionnaire survey of the stakeholders in OGP projects in Iraq (Kraidi et al. 2019b).

3- Finally, the Risk Index (RI) values of the IRFs were estimated using the fuzzy inference system toolbox in MATLAB (Kraidi et al., 2019c, 2018).

The findings of Part (I) of the flowchart, which are the identified IRFs and their RI values, are shown in table 1.

Table 1:

The results of identifying and assessing the IRFs.

\begin{tabular}{ll|ll}
\hline IRFs & RI & IRFs & RI \\
\hline Terrorism and sabotage & 3.99 & Easy access to pipeline & 3.57 \\
Corruption & 3.87 & Limited warning signs & 3.56 \\
Low public legal and moral awareness & 3.80 & Little research on this topic & 3.55
\end{tabular}




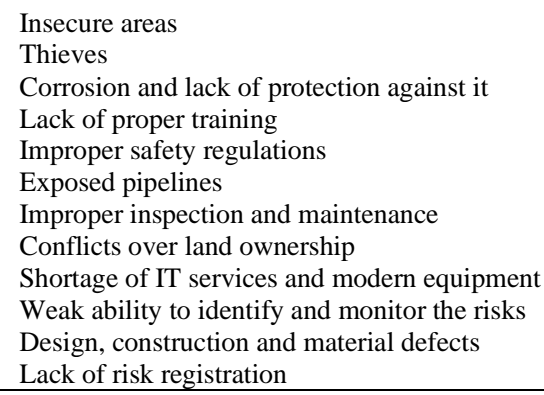

\begin{tabular}{l|ll}
3.76 & Lawlessness & 3.54 \\
3.75 & Stakeholders not paying proper attention & 3.51 \\
3.72 & Public poverty and education level & 3.49 \\
3.71 & Inadequate risk management & 3.48 \\
3.70 & Leakage of sensitive information & 3.38 \\
3.70 & Threats to staff & 3.35 \\
3.69 & Operational errors & 3.30 \\
3.68 & Geological risks & 3.17 \\
3.68 & Natural disasters and weather conditions & 3.10 \\
3.67 & Hacker attacks on the operating or control systems & 3.03 \\
3.64 & Vehicular accidents & 2.80 \\
3.60 & Animal accidents & 1.95
\end{tabular}

Part (II) of the flowchart focuses on calculating the risk levels of the project activities as follows. (1) Allocating the IRFs to the project activities. The IRFs were allocated to the work activities depending on the type of IRF and the nature of the activity. Professional knowledge was used to achieve this task. The subjective and objective analysis of a technical report (FTA, 2019) was used to justify the process of risk allocation because it explained what was required in each activity, the nature of each activity and the potential IRFs that could affect that activity based on vast experience and a review of the construction of OGP projects worldwide. (2) Calculate the total risk in each activity using equation 1, which calculates the summation of the RI values of the IRFs allocated to the project activities. (3) Calculate the total risk of the activity from $100 \%$ using equation 2. (4) Classify the project activities based on their level of risk as follows. The activities with [0-1] total risk were considered as Very Low (VL) risk activities; the activities with [1-2] total risk have a Low (L) risk; those with [2-3] total risk have a Moderate (M) risk; those with [3-4] total risk have a High (H) risk; and those with [4-5] total risk have a Very High (VH) risk. The results of Part (II) of the flowchart are shown in table 2.

The total risk of an activity $=\sum R I$ of the relevant IRFs to the activity

...(Equation 1)

The total risk of an activity $(100 \%)=\frac{\text { The total risk of an activity }}{\sum \text { Total risk of the project }} X 100 \%$

...(Equation 2)

Table 2:

The total risk of the project's main working activities and the level of risk of these activities.

\begin{tabular}{|c|c|c|c|c|c|c|c|}
\hline Activities & $(1)^{\wedge}$ & $(2)^{*}$ & $\mathrm{RL} \neg$ & Activities & (1) & (2) & RL \\
\hline Concept and definitions & 18.11 & 0.86 & VL & Welding, fabrication and installing & 36.28 & 1.72 & $\mathrm{~L}$ \\
\hline Life-cycle plan & 71.8 & 3.41 & $\mathrm{H}$ & Sandblast & 32.82 & 1.56 & $\mathrm{~L}$ \\
\hline Choosing the route & 76.65 & 3.64 & $\mathrm{H}$ & Painting & 32.81 & 1.56 & $\mathrm{~L}$ \\
\hline Route approval & 73.14 & 3.47 & $\mathrm{H}$ & Coating & 54.69 & 2.60 & M \\
\hline Design and development & 43.44 & 2.06 & M & Lowering pipe and backfilling & 46.71 & 2.22 & M \\
\hline Installation procedure & 29.28 & 1.39 & $\mathrm{~L}$ & Cathodic protection of the pipe & 68.64 & 3.26 & $\mathrm{H}$ \\
\hline Risk assessment & 49.67 & 2.36 & M & Final fitting & 32.61 & 1.55 & $\mathrm{~L}$ \\
\hline Time schedule & 22.08 & 1.05 & $\mathrm{~L}$ & As-built survey & 32.48 & 1.54 & $\mathrm{~L}$ \\
\hline Cost estimation & 22.08 & 1.05 & $\mathrm{~L}$ & Hydro, pressure test & 29.1 & 1.38 & $\mathrm{~L}$ \\
\hline Communications & 25.43 & 1.21 & $\mathrm{~L}$ & Backfilling & 36.16 & 1.72 & $\mathrm{~L}$ \\
\hline Materials order & 18.41 & 0.87 & VL & Fencing and signage & 61.49 & 2.92 & M \\
\hline Survey, staking and setting out & 75.77 & 3.60 & $\mathrm{H}$ & Final clean-up & 40.11 & 1.90 & $\mathrm{~L}$ \\
\hline Clearing and grading the right-of-way & 73.46 & 3.49 & $\mathrm{H}$ & Right-of-way reclamation & 54.03 & 2.57 & M \\
\hline Topsoil stripping & 57.88 & 2.75 & M & Safety barriers & 55.53 & 2.64 & M \\
\hline Buildings, roads and river crossings & 76.63 & 3.64 & $\mathrm{H}$ & Operation within design limits & 97.54 & 4.63 & VH \\
\hline Pipe transportation to site & 59.02 & 2.80 & M & Commissioning operation value & 97.54 & 4.63 & VH \\
\hline Temporary fencing and signage & 51.09 & 2.43 & M & Measure the project's efficiency & 29.26 & 1.39 & $\mathrm{~L}$ \\
\hline Trenching & 54.05 & 2.57 & $\mathrm{M}$ & Enhance the project's efficiency & 97.54 & 4.63 & VH \\
\hline Trench side support & 57.48 & 2.73 & $\mathrm{M}$ & Monitoring and inspection & 42.57 & 2.02 & M \\
\hline Pipe set-up & 43.84 & 2.08 & M & Maintenance & 59.54 & 2.83 & $\mathrm{H}$ \\
\hline NDT tests & 32.77 & 1.56 & $\mathrm{~L}$ & Risk control & 36.31 & 1.72 & $\mathrm{~L}$ \\
\hline
\end{tabular}


Part (III) of the flowchart shows the finding of the risk simulation and the impact of the IRFs on the duration of the project using MCS. The next section explains how the MSC works to simulate the IRFs in the projects.

\section{Application of Monte Carlo Simulation (MCS) to analyze the IRFs}

A risk simulation model integrated within ASTA Powerproject was used in this study to quantify the impact of the IRFs on the duration of the gas pipeline project. After allocating the IRFs to the work activities of the project, the simulation model will calculate the duration of each activity by applying the iterations between the minimum and maximum duration of the activity using MCS (Keramat and Kielbasa, 1997). The model has considered four different types of risk distribution: Uniform, Normal, Skewed Normal and Skewed Triangular. In the Uniform distribution method, the probability values of the activities fall between the minimum and maximum duration and have equal likelihood (Mun, 2015). In the Normal distribution method, there are three parameters, which are the minimum, the peak and the maximum values. If the peak value falls in the middle of the distribution, it means the distribution is normal (Mun, 2015). The Skewed Normal distribution is similar to the normal distribution, but it is extended by an additional shape parameter, which regulates the skewness and allows for a continuous variation from the normality to non-normality (Kumar and Anusree, 2015). The Skewed Triangular distribution method is similar to the Skewed Normal, but the results are most likely to fall on specified durations, which means the results will move further and further from the predicted results and become less likely (Bhunya et al., 2004). Figure 2 shows the four types of risk distribution.

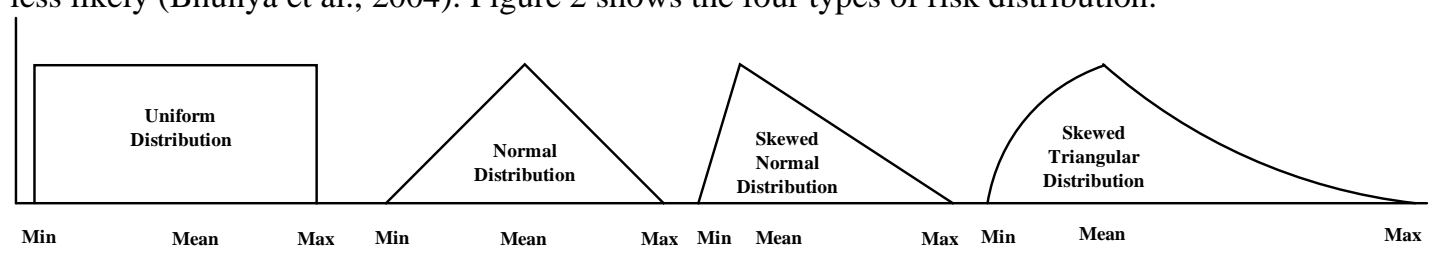

Figure 2. Uniform, Normal, Skewed Normal and Skewed Triangular risk simulation.

The impact levels of the IRFs on the project duration were set up at five different levels of risk variation as follows. (I) VH risk [75\% - 125\%] varies in a task duration when considering all IRFs. Similarly, (II) $\mathrm{H}$ risk [80\% - 120\%], (III) M risk [85\% -115\%], (IV) L [90\% - 110\%] and (V) VL [95\% - 105\%] variation are assumed on each task based on the experts' advice and industry survey findings. The results of the risk simulator are discussed in the next section.

\section{Results}

The initial planned duration of the project was 3 years and 238 days (1334 days). After analyzing the potential IRFs that affect the work activities of the project, it was found that the average delay in the project is 15 days considering the Uniform risk distribution. The delay means that the project will take 1349 days to complete rather than the planned 1334 days, which means it is expected to be completed on January 28, 2023, with 50\% probability, shown in figure 3. The Standard Deviation (Std.) of the distribution is 22 days. This means there is a $68 \%$ probability that the project will be finished between 1327 and 1371 days, whereas 95\% probability between 1305 and 1393 days (see figure 3). For details of the case study, results are presented in table 3. 
Table 3:

The project duration (days) after analyzing the IRFs with work activities of the project.

\begin{tabular}{lllllllllll}
\hline Distribution & Mean Duration^$^{\wedge}$ & Delay & Std & \multicolumn{2}{c}{ Mean duration \pm Std. } & \multicolumn{2}{c}{ Mean duration $\pm(2 *$ Std.) } & Max hits \\
\hline Uniform & 1349 & 15 & 22 & 1327 & And & 1371 & 1305 & And & 1393 & 303 \\
Normal & 1349 & 15 & 21 & 1328 & And & 1370 & 1307 & And & 1391 & 316 \\
Skewed Normal & 1348 & 14 & 22 & 1326 & And & 1370 & 1304 & And & 1392 & 323 \\
Skewed Triangular & 1348 & 14 & 21 & 1327 & And & 1369 & 1306 & And & 1390 & 314 \\
\hline
\end{tabular}

Figure 3 shows the simulation results with the minimum, the mean and the maximum probability of project completion dates after considering the impact of the IRFs. The graphs of the finish dates' likelihood and distribution are based on using the Uniform distribution and MSC method at 10,000 iterations. The maximum hits rate is 303 , which reflects the mean value of the project duration. The project has a $50 \%$ probability of being completed on the mean duration, as the date is shown in figure 3.

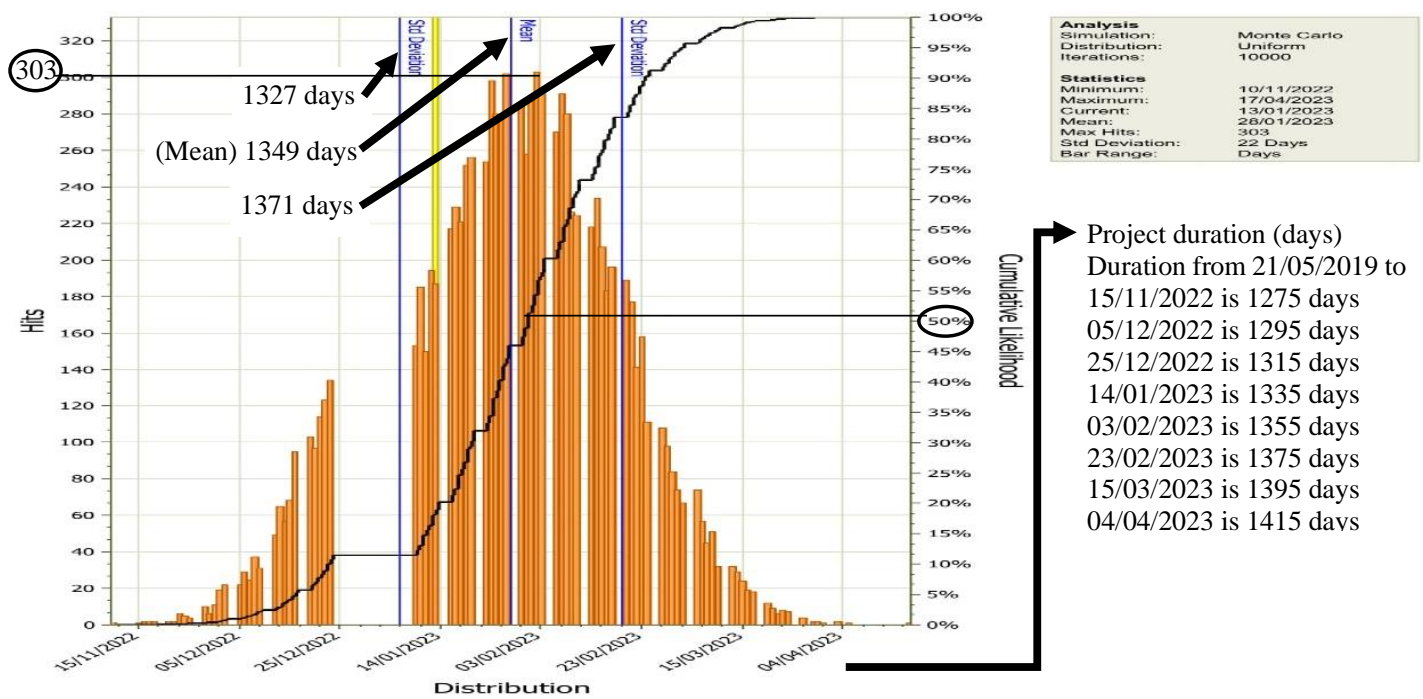

Figure 3. Finish date likelihood and distribution using the Uniform data distribution method.

Furthermore, the construction of the project commenced on May 21, 2019 instead of April 1, 2019 due to the delay in signing the contract between the government and the construction company. Consequently, the project started later than the original plan and causes 51 days delay in real life. Such IRFs are beyond the authors' knowledge and needed to be managed from very high levels of government. Therefore, such an exceptional delay has not included in the simulation model with the case study. Table 4 presents a real-life project delay in addition to the delay caused by IRFs in the OGPs project below.

Table 4:

The comparison of project delay between the research's findings and real-life delay in the project.

\begin{tabular}{lcll}
\hline Impact delay in project & Real life project & Case study results & Delay \\
\hline Research findings & 1334 days $\neg$ & 1349 (from table 3$)$ & 15 days $(+)$ (see table 3) \\
Actual delay in project & 1385 days $\neg$ & $1385+15$ (from table 3$)=1400$ days & 66 days $(+)^{*}$ \\
\hline$\neg$ The initial duration of the project, $\neg$ The delay caused by the late start of the project \\
*The real-life delay = 15 days (see table 3) +51 (days) the delay that cause by late start of the project = 66 days. \\
\hline
\end{tabular}

Correspondingly, the real delay in the project was 51 days (real life delay). In addition to the real-life delay, the expected delay in the project due to the impact of the IRFs is 15 days (case study results). 


\section{Discussion and Conclusion}

This paper has provided risk simulation results based on a comprehensive risk analysis approach. The potential IRFs in the OGP project were identified based on a widespread literate review in different environments and circumstances worldwide. The IRFs were analyzed based on the perceptions of the stakeholders associated with OGP projects. Fuzzy logic theory was used to estimate the RI values of the IRFs, which reduces the uncertainty associated with the risk analysis and overcomes the data scarcity problem and the prejudices in stakeholders' judgements about their level of impact. The average delay in the gas pipeline project after considering the IRFs within work activities of this project is between 14 and 15 days from the planned project duration using the four methods of risk distribution. The difference between the risk simulation and data distribution methods in this case study was minimal, which means making a comparison between the distribution methods to choose the one that gives a better result is challenging. The literature review found that the past studies analyzing the delay factors in construction projects are limited to certain regions of study. This makes them ineffective when analyzing the IRFs in construction projects in a different place, especially in areas that have different characteristics of risk factors affecting the projects. The different characteristics of the IRFs result from the poor documentation in developing countries about the IRFs in the projects, which means that data essential for risk management (e.g. the IRFs and their levels of RP and RS) is not available. Additionally, there are IRFs that result from the low security levels in countries like Iraq; this situation obstructs the risk management efforts in OGP projects in these regions.

This paper has examined the IRFs associated with OGPs at the execution stage of these projects. The approach adopted for identifying and analyzing the IRFs in OGP projects will help to provide the stakeholders with the necessary knowledge to understand the IRFs in their projects. Providing trusted data and a proper understanding of the IRFs will help the stakeholders, the decision-makers and the policy-makers of the projects to make suitable policies and take the correct actions related to risk management. Having an active risk management system helps in avoiding and/or minimizing project delay during the construction stage and improves the safety level of these projects during the operation stage as well. This paper has considered only four methods of risk distribution, but only one distribution method could be applied on time during the process of risk simulation, which means the process of risk simulation was repeated four times. This is one of the limitations of the study. Therefore, in future work, the IRFs will be analyzed using the @ Risk simulator, which helps to apply different distribution methods for each IRF and activity at the same time, which will enhance the risk simulation results and add more confidence regarding the project completion probability.

The IRFs associated with the OGPs projects all over Iraq were investigated and ranked. This provides a wide knowledge about the IRFs and their impact on OGPs projects across the country. This paper has evaluated a pipeline project in Iraq that covers $164 \mathrm{~km}$, which is a long pipeline that crosses different regions with different topographies and safety environments. This has helped to quantify the impact on project delay in OGP projects in the south of Iraq. The IRFs might have a slightly different impact on the OGPs in different regions in the country. As this paper has analyzed the delay in on going project, the future work, therefore, will analyze the real life delay and the causes behind this delay when the project finishes. Moreover, the future work will focus on the cost impact of the IRFs in these projects.

Acknowledgements: The authors are grateful for the financial support from the Ministry of Higher Education and Scientific Research, and University of AL-Muthanna Iraq.

\section{References}

Alaghbari, W., Razali A. Kadir, M., Salim, A., and Ernawati. (2007). The significant factors causing delay of building construction projects in Malaysia. Engineering, Construction and Architectural Management, 14, pp 192-206.

Bhunya, P., Mishra, S., Ojha, C., and Berndtsson, R. (2004). Parameter Estimation of Beta Distribution for Unit Hydrograph Derivation. Journal of Hydrologic Engineering, 9(4), pp. 325-332. 
Choong Kog, Y. (2018). Major Construction Delay Factors in Portugal, the UK, and the US. Practice Periodical on Structural Design and Construction, 23(4), pp. 04018024-1-8.

FracTracker Alliance (FTA). (2019). Pipeline Construction: Step-By-Step Guide [Online]. Available at https://www.fractracker.org/resources/oil-and-gas-101/pipeline-construction/

Fallahnejad, M. (2013). Delay causes in Iran gas pipeline projects. International Journal of Project Management, 31(1), pp. 136-146.

Prasad, K., Vasugi, V., Venkatesan, R., and Bhat, N. (2019). Analysis of causes of delay in Indian construction projects and mitigation measures. Journal of Financial Management of Property and Construction, 24(1), pp 58-78.

Kadry, M., Osman, H., and Georgy, M. (2017). Causes of Construction Delays in Countries with High Geopolitical Risks. Journal of Construction Engineering and Management. 143(2), pp 04016095-1-11. Keramat, M., and Kielbasa, R. (1997). Latin Hypercube Sampling MC Estimation of Average Quality Index for Integrated Circuits. Analog Integrated Circuits and Signal Processing, 14, pp131-142.

Kraidi, L., Shah, R., Matipa, W., Borthwick, F. (2017). Analysing the Critical Risk Factors of Oil and Gas Pipeline Projects in Iraq. In The Proceedings of the 3rd BUiD Doctoral Research Conference, British University in Dubai, the $13^{\text {th }}$ of May 2017, Dubai. pp. 133-148.

Kraidi, L., Shah, R., Matipa, W., and Borthwick, F. (2019a). Analyzing the critical risk factors associated with oil and gas pipeline projects in Iraq. International Journal of Critical Infrastructure Protection, 24, pp. 14-22.

Kraidi, L., Shah, R., Matipa, W., and Borthwick, F. (2019b). Analyzing Stakeholders' Perceptions of the Critical Risk Factors in Oil and Gas Pipeline Projects. Period Polytech Archit.

Kraidi, L., Shah, R., Matipa, W., and Borthwick, F. (2018). An Analysis of the Critical Risk Factors in Oil and Gas Pipeline Projects Using a Comprehensive Risk Management Framework. This Paper Was Presented as a Working Paper at the ARCOM 34th Conference, 3-5 September. Belfast, UK.

Kraidi, L., Shah, R., Matipa, W., Borthwick, F. (2019c). Application of Fuzzy Logic Theory on Risk Assessment in Oil and Gas Pipeline Projects. In Proceedings of the 55th Annual ASC Conference, 1013 April. Denver, Colorado, USA.

Kumar, C., and Anusree, M. (2015). On an Extended Version of Skew Generalized Normal Distribution and Some of its Properties. Communications in Statistics, Theory Methods, 44, pp. 573-586.

Morano, C., Martins, C., and Ferreira, M. (2006). Application of techniques for the identification of risk in the E\&P ventures Engevista. In $5^{\text {th }}$ Management of Technological Change Conference - MTC 2007. Alexandrou polis, Greece, 8, pp. 120-133.

Mpofu, B., Ochieng, E., Moobela, C., and Pretorius, A. (2017). Profiling causative factors leading to construction project delays in the United Arab Emirates. Engineering, Construction and Architectural Management, 24(2), pp 346-376.

Mun, J. (2015). Understanding and Choosing the Right Probability Distributions, In Advanced Analytical Models, John Wiley \& Sons, Inc., Hoboken, NJ, USA, pp. 899-917.

Ruqaishi, M., and Bashir, H. (2015). Causes of Delay in Construction Projects in the Oil and Gas Industry in the Gulf Cooperation Council Countries: A Case Study. Journal of Management in Engineering, 31(3), pp 5014017-1-8.

Ruwanpura, J., Ariaratnam, S., and El-assaly, A. (2004). Prediction models for sewer infrastructure utilizing rule-based simulation. Civil Engineering and Environmental Systems, 21(3), pp169-185.

Shah, R. (2016). An Exploration of Causes for Delay and Cost Overruns in Construction Projects: Case of Australia, Malaysia \& Ghana. Journal of Advanced College of Engineering \& Management, 2, pp 41-55.

Shebob, A, Dawood, N., and Shah, R. (2012). Development of a methodology for analysing and quantifying the impact of delay factors affecting construction projects. Journal of Construction Engineering and Project Management, 2(3), pp. 17-29.

Sweis, R., Moarefi, A., Amiri, M., Moarefi, S., and Saleh, R. (2019). Causes of delay in Iranian oil and gas projects: a root cause analysis. Inter. Journal of Energy Sector Management, 13(3), pp. 630-650. 